\title{
Antropología cultural de Castellón y su provincia
}

\author{
Pilar Escuder Mollón \\ Universitat Jaume I, España \\ mollon@uji.es
}

La revista Ariadna tiene como principal objetivo la divulgación del conocimiento, en el contexto científico y cultural, incluyendo por tanto el antropológico. Durante una investigación antropológica, se pretende conocer el entorno, nuestra historia, el arte, la cultura y las tradiciones.

Los estudiantes de la Universitat per a Majors asisten de forma habitual a la docencia que se oferta, pero las inquietudes de un alumno no deben desaparecer cuando sale del aula y las dudas y su interés por aprender se extienden mas allá de la duración de la clase. Es por eso que un alumno debe ser entendido como una persona activa que observa, percibe y analiza todo esto para seguir aprendiendo en un sentido amplio de la palabra, mejorando aquello que hace o alcanzando una comprensión mayor del entorno.

Este número de Ariadna está realizado íntegramente por estudiantes de la Universitat per a Majors. Son ellos quienes, de forma tutorizada, han investigado sobre temas que les eran de especial interés y las aportaciones más significativas han sido incorporadas a este número especial de Ariadna. otras personas y generaciones puedan aprovecharlos y disfrutarlos.

El aprendizaje solo tiene sentido si el estudiante es una persona activa, capaz de absorber lo que aprende y adquirir nuevas habilidades y competencias. No obstante, sería una verdadera lástima si este mismo estudiante no desarrollara en sí capacidades e inquietudes para aumentar sus conocimientos, expandirlos y compartirlos. Esta actividad altruista es muy beneficiosa para la comunidad y la sociedad en general, la cual tiene a su disposición nueva información, pero también para el propio alumno, que puede rentabilizar y promover un uso a su conocimiento.

La Universitat per a Majors siempre ha promovido este aprendizaje activo, ofertando actividades, tutorizando trabajos de investigación y facilitando medios como esta revista o herramientas de Internet para que el conocimiento se aplique y crezca, dando sentido al aprendizaje permanente.

En primer lugar, estas aportaciones representan un paso más en su formación como personas, como alumnos inquietos $\mathrm{y}$ motivados por su interés de comprender con mayor profundidad y objetividad ciertos aspectos del entorno que les resultan de especial relevancia. En segundo lugar, la edición de esta revista, con estos trabajos, obedece también a un objetivo tan importante como es el de enseñar. Nuestro conocimiento y experiencia no deben ser retenidos ni guardados, deben ser transmitidos en la medida de lo posible, para que

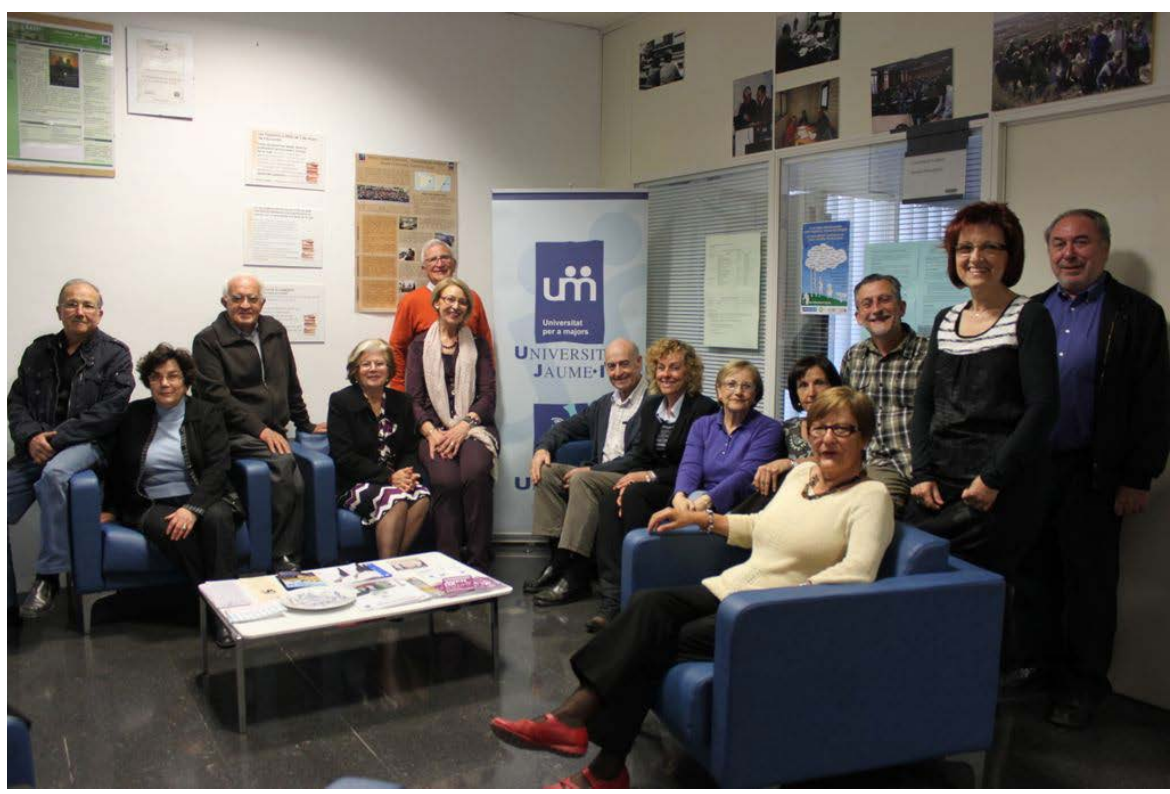

Grupo de alumnos integrantes del grupo de antropología 